Research Article

\title{
Empirical Study of the Relationship between Financial Development and Economic Growth Based on Intelligent Algorithms Based on Wireless Network Communication
}

\author{
Juan Xie $\mathbb{D}$ and Yunfei Cao \\ Faculty of Economics, Sichuan University, Chengdu 610065, Sichuan, China \\ Correspondence should be addressed to Juan Xie; xiejuan@stu.scu.edu.cn
}

Received 7 August 2021; Revised 15 September 2021; Accepted 23 September 2021; Published 8 October 2021

Academic Editor: Sang-Bing Tsai

Copyright (c) 2021 Juan Xie and Yunfei Cao. This is an open access article distributed under the Creative Commons Attribution License, which permits unrestricted use, distribution, and reproduction in any medium, provided the original work is properly cited.

\begin{abstract}
In order to discuss a series of issues surrounding financial development and economic growth, it makes it more meaningful to discuss regional financial development and economic growth. This article aims to study the empirical study of the relationship between financial development and economic growth based on intelligent algorithms based on wireless network communication. In this article, a two-side positioning model is established, and the optimal solution is found for the feasible region through the particle swarm optimization algorithm. After two anchor nodes are realized, the position of the unknown node can be calculated. In addition, this article uses the Shadowing model to calculate the distance between wireless network nodes. This model is composed of path loss and occlusion factors, which can fully consider the impact of environmental factors on the signal. Experimental research data show that the improved algorithm has a positioning coverage close to $100 \%$ when the anchor node density is $30 \%$. The improved algorithm in this article speeds up the convergence speed than positioning algorithm 1 and reduces the time by about $35 \%$. Although the running time of the algorithm in this article is longer than that of positioning algorithm 2 , the overall positioning accuracy is higher than that of the positioning algorithm, which is about $20 \%$ higher.
\end{abstract}

\section{Introduction}

The progress of society and science has promoted the development of the Internet of Things technology and the continuous expansion of its application range. The Internet of Things has slowly penetrated into all areas of our lives. It can be said that the application of the Internet of Things is ubiquitous in life. Since the introduction of wireless sensor technology in the Internet of Things, the Internet of Things has broken through the bottleneck in many traditional applications, allowing the Internet of Things to develop more extensively and in depth. Its applications include smart cities, military technology, environmental monitoring, and space exploration. Wireless Sensor Networks (Wireless Sensor Networks, WSN) is a distributed sensor network, the end of which is a sensor that can perceive and inspect the outside world. The sensors in WSN communicate wirelessly, so the network settings are flexible, the location of the device can be changed at any time, and it can also be connected to the Internet in wired or wireless mode. A multihop selforganizing network was formed by wireless communication. Wireless sensor network has the advantages of rapid deployment, good concealment, strong self-organization, and low price. It is very suitable for target tracking, identification, positioning, and other applications. Node positioning is an important part of these applications, and it is also the premise and foundation. As an emerging technology, wireless sensor network target positioning has been successfully applied in military fields such as cyber-centric warfare in the United States, showing great research value and significance, and it has become a research hotspot in the IT field at home and abroad.

As a means of capital allocation, finance plays a decisive role in capital allocation. Finance not only has the ability to 
allocate economic resources in the economic system but also can gather idle social funds, diversify the risks of the company, and can also play a role in supervision. Throughout the world, international metropolises, such as New York, London, Hong Kong, Singapore, Tokyo, and so on, all play an equally important role in the world-financial centers. Since 1978, the short-term upward shift of China's Phillips curve shows that China has gradually shifted from a planned economy to a market economy in the past, and the price level has tended to a reasonable position. In 1997, the Asian financial crisis had a big impact on our country. There was deflation in our country. State-owned enterprises were forced to lay off their employees due to reforms. Private enterprises were insufficiently vigorous. It was not until 1999 that the economy began to pick up. Affected by the US financial crisis in 2008, my China's economic development has slowed down, and the inflation rate has dropped sharply. However, due to the country's active adoption of macroeconomic policies to ensure employment, China's unemployment rate has not risen much. Therefore, to a certain extent, the level of financial development has become an important constraint for the development and prosperity of a region or country. As China's economic development enters a new normal, economic restructuring is gradually unfolding. While economic development adheres to reform and opening up, it also continuously optimizes and upgrades the financial service industry in order to better support the development of the real economy. All in all, the adjustment of economic policies is aimed at mobilizing the positive factors contained in finance, optimizing the allocation of factors to improve the efficiency of use, so as to introduce the service sector to foreign countries and improve the development level of the entire economy. More is to focus on optimizing the structure and reform in the direction of indepth adjustment, and the driving force of economic development urgently needs to find a new breakthrough. It can be seen that the contribution of finance in modern social and economic life is increasing, and the issue of financial development has gradually become a hot topic in our country's development.

Nowadays, finance is developing more and more rapidly, so that more and more researchers are studying it. The Swaour V study explored the causal relationship between financial development and economic growth in advanced economies because the level of financial development in these countries has increased significantly. Using an alternative method of mitigating the intermediary effect framework, the policy implication is the need to control inflation and real interest rates and increase trade openness, in order to optimize the benefits of growing financial development to economic growth. However, the development of this principle in practical applications is still not mature enough [1]. Nkoa proposed a system for providing wireless telecommunication services to mobile devices, including structures and functions for location-based services, and including servers and client/mobile device devices. An apparatus includes a data storage that stores at least a first record associated with a first wireless device or a second record associated with a second wireless device. The computer is configured to receive the request to change the location permission and update the first or second record in the data store based on the received change request [2]. Kalloub et al. proposed the Age of Information (AoI) as an indicator recently used to measure the freshness of information. AoI measures the elapsed time since the last received update was generated. He showed that the fixed scheduling strategy is the optimal peak age. In the case where fresh information is not always available, it is necessary to control the packet/information generation rate and the transmission scheduling link, which proves an important separation principle: the optimal scheduling strategy can be designed assuming fresh information and, independently, data packets. The generation rate control can be done by ignoring interference [3]. Nyasha and Odhiambo believed that improving spectrum efficiency and ensuring high quality of service (QoS) and high quality of experience (QoE) are key issues for wireless communications. Taking into account the radio conditions and user requirements in the allocation process, the recognized best opportunity resource allocation scheduler allows these goals to be achieved. He proposed an optimized trade-off between energy, throughput, and fairness, thanks to a new opportunistic method that combines the advantages of specialized schedulers without disadvantages [4]. Moghadam and Dehbashi has developed a new type of exchange excuse system. They provided a unified wireless network service selection information exchange interface system to promote a consistent user experience across multiple wireless networks that may have different service plan activation or service plan purchase processes; also they provided network detection of abnormal service usage based on device-based data usage reports, so that the network can determine whether the end-user device may operate in accordance with established policies or whether the end-user device may be operating fraudulently [5]. Dewi et al. introduced the synergy and complementary characteristics of big data and $5 \mathrm{G}$ wireless networks. It outlines their interactions, including big data-driven networks and big data auxiliary networks. To further illustrate mutual benefits, two case studies on network-assisted data collection and big data-assisted edge content caching are provided. Finally, some interesting open research questions were discussed [6]. Riache et al. aimed to improve the throughput and reliability of $5 \mathrm{G}$ wireless cloud radio access network (CRAN) through the collaborative combination of diversity coding and network coding (DC-NC). The results show that the combination of diversity and network coding increases the throughput of the fronthaul network for downlink broadcast or multicast applications, and at the same time, through the use of forward error control across different paths in space, a near-instant delay is achieved in failure recovery. In addition, using the proposed scheme can reduce the number of redundant links inherent in diversity coding [7].

The creation of this article is as follows: (1) When studying financial development and economic growth, not only the factors of financial development and economic growth are considered but also the influence of human capital, capital stock, and import and export three control 
variables are added. This makes the perspective of the problem considered more comprehensive, and the conclusions drawn will be more convincing. (2) The consideration of geospatial effects has been added. When studying the relationship between financial development and economic growth between cities, the geographical weight matrix is added to analyze the problem, considering the relevance of variables in space, and exploring the problem in a new direction. (3) Establish a two-side positioning model, find the optimal solution for the feasible area through the particle swarm optimization algorithm, and calculate the position of the unknown node after two anchor nodes are realized. Simulation experiments show that compared with the traditional trilateral positioning algorithm, the algorithm significantly improves the positioning accuracy and positioning coverage without increasing the calculation time. Based on the VAR model, the results are discussed through the analysis of different sets of data. Use interprovincial and regional macroeconomic data and the overall financial development and economic growth of the region to compare and analyze research results between regions.

\section{Empirical Research Method of the Relationship between Financial Development and Economic Growth Based on Intelligent Algorithms of Wireless Network Communication}

2.1. Architecture of Wireless Sensor Network. As shown in Figure 1, it is the architecture of the wireless sensor network. Sensors provide energy through their own microbatteries, so they cannot support higher computing, communication, and storage capabilities. The data processing module processes the collected data according to the needs of users [8]. The wireless communication module sends and receives information between nodes. One of the other important applications of wireless networks is to provide a cheap and fast channel to connect to the Internet in countries and regions where basic telecommunications construction is poor or lacking resources. Most developing countries will have it.

Sensors have resource and design constraints [9]. In sensor nodes, there are mainly resource limitations, such as energy limitation, low computing power, and short communication distance; nodes are used in a variety of different environments, and generally, they do not deliberately design nodes that adapt to the environment according to different environments. But compared with traditional wireless network, it has some distinctive features of its own [10].

(1) In order to obtain the information of the monitoring area more comprehensively, the number of sensor nodes may reach thousands or even more.

(2) Self-organization in actual monitoring is generally randomly placed in some inaccessible areas to be monitored. After the deployment of the sensor node, it first detects its neighbor nodes and establishes communication and then spontaneously selects the appropriate layered protocol and topological structure to establish communication channels and send data, forming a dynamic network.

(3) Dynamic changes in the external environment and the sensor nodes themselves will affect the changes in the network topology. The specific influencing factors are as follows:

(1) Quit the network due to node failure.

(2) The network needs to add new nodes.

(3) Changes in environmental conditions may affect the quality of network communication and even short-term network communication interruptions.

(4) The sensing object of the sensor network or the location of the monitoring node changes [11].

(5) The catenary is an open-air device, which is greatly affected by natural conditions (wind, rain, ice, fog, temperature). The surrounding environment, such as upper bridges, upper power lines, dangerous towers, and dangerous trees affects the structure of the network topology.

(4) Taking data as the center. Because nodes are randomly deployed in the monitoring environment, when users need to query events, they will not inform a certain node in the network but the entire network of the event they are concerned about. What is observed in the monitoring area is environmental information, and the work is carried out around the collection and transmission of information. So the wireless network is data centric [12].

(5) Resources are limited to most currently deployed in environmental monitoring, whose nodes are stationary, especially in areas where poor environment or humans cannot reach, and it is unrealistic to recharge the nodes [13].

2.2. RSSI Ranging Principle. Nodes are randomly deployed in monitoring areas where the environment is poor or people cannot reach. Reducing the number of anchor nodes in the network can reduce network costs and manual operation and maintenance costs. It is a relatively simple and intuitive way to calculate the distance between nodes through signal attenuation [14]. Received signal strength indication, an optional part of the wireless transmission layer, is used to determine the link quality and whether to increase the broadcast transmission strength. A positioning technology that can determine the distance between the signal point and the receiving point through the strength of the received signal and then perform positioning calculations based on the corresponding data. However, it is found in the measurement that the received signal measurement value is unstable, and the RSSI value fluctuates greatly, which affects the positioning accuracy of the node [15]. At the same time, the distribution of some nodes is not uniform, and there will be large positioning errors in low anchor node density areas or even unable to locate. In response to the above problems, this chapter first corrects the RSSI ranging 


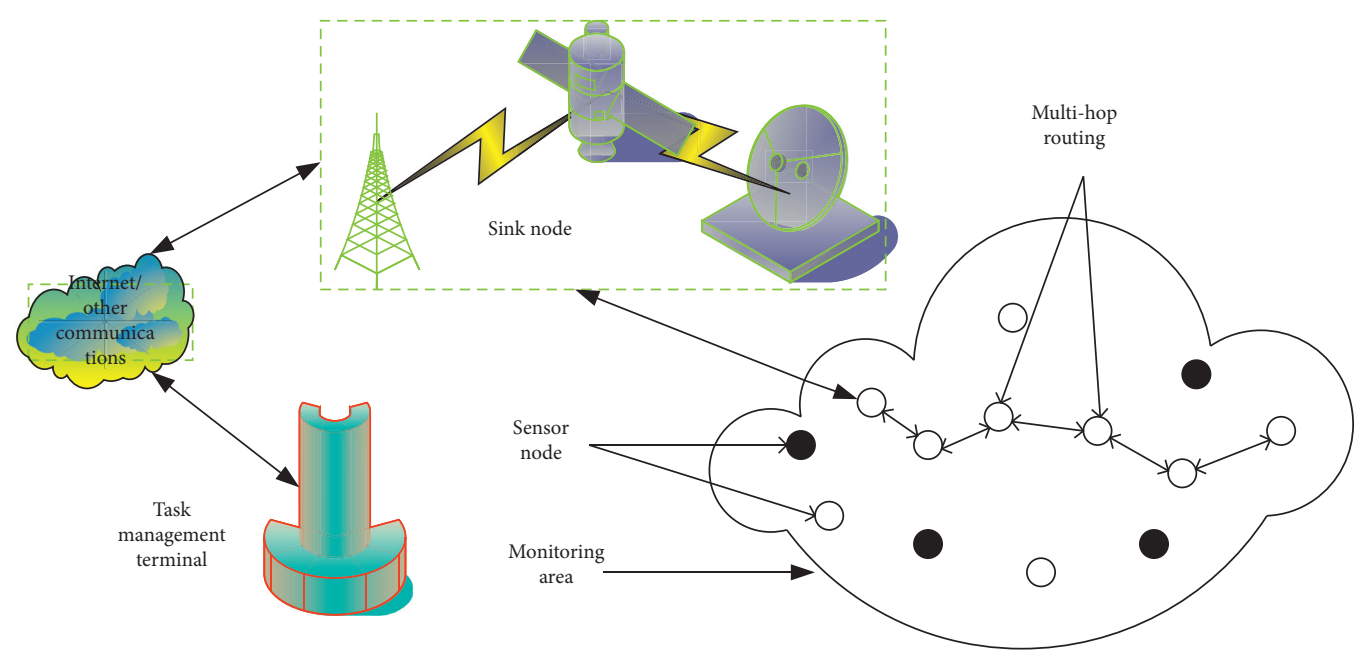

Anchor node

Unknown node

FIgURE 1: Wireless sensor network architecture.

accuracy, and then, when there are only two anchor nodes for unknown nodes that can participate in positioning, establish a two-sided positioning model and optimize the feasibility area of the two-sided positioning through the particle swarm optimization algorithm [16]. Because the sensor nodes are randomly distributed in the wireless sensor network, the positioning error of the distance vector hop positioning algorithm is too large; for this reason, the method of hop count and hop distance correction is used to improve the distance vector hop positioning algorithm. In the process of beacon node and unknown node's hop count, the influence of node communication distance is introduced, which makes the calculation of actual hop count between nodes more accurate [17].

As shown in Figure 2, during the positioning process, the nodes communicate with each other and collect the signals of other nodes. The signal strength of the collected nodes is converted into the distance through the signal model, and then, the unknown is calculated by the corresponding positioning calculation method. In the whole positioning process, the most important thing is to choose a suitable signal model to calculate the distance between nodes. The accuracy of ranging directly affects the accuracy of positioning nodes. Choosing a suitable ranging model will help reduce the positioning error [18].

Among them, the Shadowing model is relatively simple and comprehensively considers the influence of environmental factors on the signal [19]. Therefore, this article uses the Shadowing model to calculate the distance between nodes. The shadow effect refers to the formation of a semiblind area on the propagation receiving area due to large buildings and other objects blocking the transmission path of radio waves when the mobile station is in motion in the wireless communication system, thus forming electromagnetic field shadows. The fluctuation of the median field strength of the receiving point caused by the continuous change of the mobile station's position is called the shadow effect. The shadow effect is the main cause of slow fading.
The path loss formula in the previous part is as follows:

$$
\frac{Q_{r}\left(d_{0}\right)}{Q_{r}(d)}=\frac{d}{d_{0}},
$$

where $Q_{r}(d)$ and $Q_{r}\left(d_{0}\right)$ represent the average energy of the received signal when the distance from the transmitting node is $d$ and $d_{0}$, respectively.

$$
\left[\frac{Q_{r}\left(d_{0}\right)}{Q_{r}(d)}\right]_{d b}=-10 n \lg \left(\frac{d}{d_{0}}\right),
$$

$n$ is the path loss index, which is related to environmental factors, and generally takes 2 to 5 . The second half of the Shadowing model is an occlusion factor, which obeys a normal random distribution variable. It is used to represent the influence of environmental noise on the signal, and its unit is $\mathrm{dB}$ [20]. The entire Shadowing model is

$$
\left[\frac{Q_{r}\left(d_{0}\right)}{Q_{r}(d)}\right]_{d b}=-10 n \lg \left(\frac{d}{d_{0}}\right)+\delta .
$$

The impact of non-line-of-sight on RSSI is the main one, so the occlusion factor $\delta$ is usually not considered. Simplification can be obtained:

$$
Q=Q_{0}-10 k \lg \left(\frac{d}{d_{0}}\right)
$$

For convenience, the reference distance $d$ is usually taken as $1 \mathrm{~m}$, and the simplified formula of RSSI ranging is obtained:

$$
\text { RSSI }=-(B+10 n \lg d) .
$$

The unit of RSSI is $d B$, and $B$ represents the signal strength value received at $1 \mathrm{~m}$ from the transmitting center. Then, the distance between two nodes can be calculated:

$$
d=10^{-((B+R S S I) / 10 * n)} .
$$




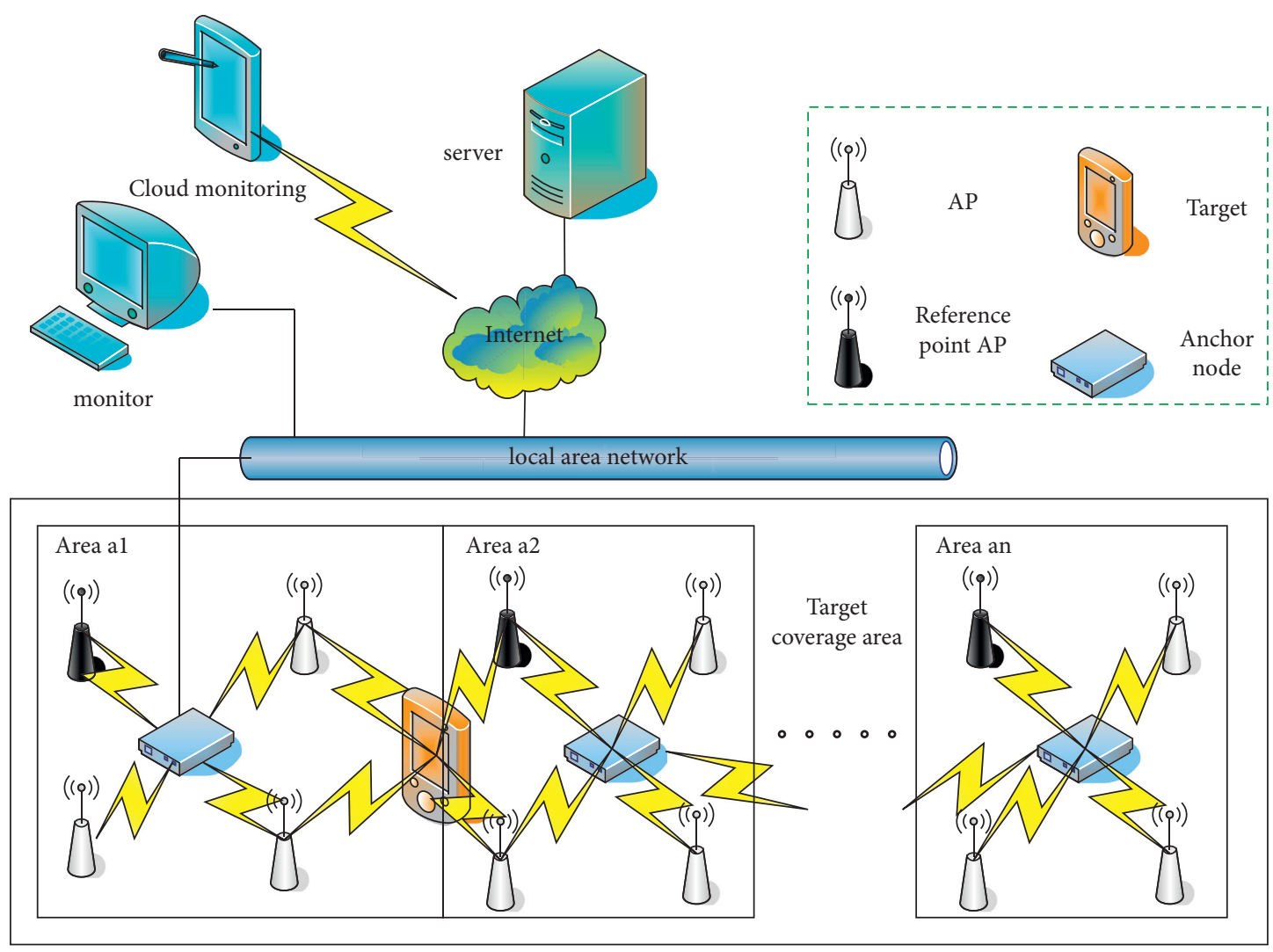

FIGURE 2: RSSI ranging and positioning steps.

Gaussian filtering is a linear smoothing filter, which is suitable for eliminating Gaussian noise and is widely used in the denoising process of image processing. In layman's terms, Gaussian filtering is the process of weighted averaging the entire image. The value of each pixel is obtained by weighted averaging of itself and other pixel values in the neighborhood. The specific operation of Gaussian filtering is to scan each pixel in the image with a template (or convolution, mask) and use the weighted average gray value of the pixels in the neighborhood determined by the template to replace the value of the center pixel of the template. Gaussian filtering is performed on the RSSI value [21], the Gaussian function is given as

$$
g\left(\mathrm{RSSI}_{i}\right)=\frac{1}{\gamma \sqrt{2 \pi}} e^{-\left(\left(\mathrm{RSSI}_{i}-\mu\right) / 2 \gamma^{2}\right)},
$$

in

$$
\begin{aligned}
\mu & =\frac{1}{n} \sum_{i=1}^{n} x_{i}, \\
\gamma^{2} & =\frac{1}{n-1} \sum_{i=1}^{n}\left(x_{i}-\mu\right)^{2} .
\end{aligned}
$$

After Gaussian filtering, the remaining $n$ signal values $\left(\mathrm{RSSI}_{1}, \mathrm{RSSI}_{2}, \ldots, \mathrm{RSSI}_{n}\right.$ ) are sorted by numerical value, and the median RSSIm is found:

$$
\operatorname{RSSI}_{m}=\left\{\begin{array}{l}
\operatorname{RSSI}_{((n+1) / 2)}, \\
\frac{1}{2}\left(\operatorname{RSSI}_{(n / 2)}+\operatorname{RSSI}_{(n / 2)+1}\right)
\end{array}\right.
$$

Find the difference between each RSSI signal strength and the median $\mathrm{RSSI}_{m}$ :

$$
D_{i}=\left(\mathrm{RSSI}_{i}-\mathrm{RSSI}_{m}\right) \text {. }
$$

The weighting factor is

$$
R_{i}=\frac{1}{\left(1+D_{i}\right)} .
$$

Normalize the weight coefficient

$$
\omega_{i}=\frac{R_{i}}{\sum_{i=1}^{n} R_{i}} .
$$

Among them, $\mathrm{RSSI}_{i}$ is the $i$-th RSSI value, and the result obtained is used as the optimized value:

$$
\mathrm{RSSI}_{\mathrm{opt}}=\sum_{i}^{n} \mathrm{RSSI}_{i} * \omega_{i} \text {. }
$$

The RSSI value after the accuracy correction is converted into a distance. Assuming that there are two anchor nodes A and $\mathrm{B}$ around the unknown node $n$, the distances of which are $d 1$ and $d 2$, respectively. Then, the rectangles with two 
sides $d 1$ and $d 2$ intersect with a shadow area, which is solved by particle swarm optimization algorithm [22].

The two-sided positioning problem can be described as

$$
G(x, y)=\operatorname{Min}\left(\sum_{i=1, \ldots, m} \mid \sqrt{\left(x-x_{i}\right)^{2}+\left(y-y_{i}\right)^{2}}-d_{i}\right) \text {. }
$$

Among them, $(x, y)$ represents the estimated coordinates of the unknown node, and $\left(x_{i}, y_{i}\right)$ represents the coordinates of the anchor node $i$; $d_{i}$ represents the measured distance between the unknown node and the anchor node.

According to the objective function, we can convert it into a fitness function, the formula is as follows:

$$
\text { fitness }(x, y)=\frac{\beta}{G(x, y)},
$$

where $\beta$ is a positive real number.

Assuming that for each unknown node $N$, in order to determine the feasibility area of the individual, the formula is as follows:

$$
\left\{\begin{array}{l}
\max _{i=1,2}\left(x_{i}=R_{i N}\right) \leq x_{N} \leq \min _{i=1,2}\left(x_{i}-R_{i N}\right), \\
\max _{i=1,2}\left(y_{i}=R_{i N}\right) \leq y_{N} \leq \min _{i=1,2}\left(y_{i}-R_{i N}\right) .
\end{array}\right.
$$

Among them, $\left(x_{N}, y_{N}\right)$ is the coordinate of the unknown node $N$.

The fitness value of each solution is sorted and compared with the two extreme values. If the current solution is not better than the two extreme values, use the following formula to update the position of the example [23].

$$
\begin{aligned}
v_{i}(t+1)= & w * v_{i}(t)+c_{1} * r_{1}\left(p \text { Best }_{i}-x_{i}(t)\right) \\
& +c_{2} * r_{2}\left(g \text { Best }_{i}-x_{i}(t)\right) \\
x_{i}(t+1)= & x_{i}(t)+v_{i}(t+1)
\end{aligned}
$$

can be simplified to

$$
\begin{aligned}
v_{i}(t+1)= & w * v_{i}(t)+r_{1}\left(p \text { Best }_{i}-x_{i}(t)\right) \\
& +r_{2}\left(g \text { Best }_{i}-x_{i}(t)\right) .
\end{aligned}
$$

Through the prediction of the node distance, the relationship between financial development and economic growth is analyzed, and use the panel data threshold model to detect whether there is a multithreshold model of money supply, and further explore the relationship between financial deepening and economic growth in different multithreshold regions.

\subsection{Relationship between Financial Development and Eco-} nomic Growth. Regarding the relationship between financial development and economic growth, many scholars have a wide range of disputes and different views. Judging from the existing research results, their views can be roughly divided into the following categories:

(1) There is no correlation between financial development and economic growth. Han Yanchun (2001) has shown that in China, the improvement and innovation of technology and systems are the main driving force of economic growth, while financial development plays a very small role. Due to the extreme imperfection of its market, it even produces certain obstacles [24].

(2) Economic growth promotes the development of the financial industry. This is in line with the demandfollowing hypothesis. Due to the development of the industrial sector in the economy, in order to reduce transaction costs, a large number of financial industries have spawned to reduce friction in the market. With demand, financial market development [25] occurred.

(3) Financial development stimulated the increase in investment, which led to economic growth. A large number of scholars believe that the development of the former has indeed greatly promoted the prosperity of the latter, and a lot of research has been done to support this view. Levine and Zervos conducted a deeper research and discussion at the end of the twentieth century and showed that the higher the level of bank development [26], the greater the liquidity of the stock market, the faster its economic development, and the development of finance has greatly accelerated economic prosperity to a certain extent. Tan Ruyong (1999), Cao Xiao, and $\mathrm{Wu}$ Jun (2002) are also supporters of this view [27].

(4) Financial development and economic growth influence each other. After Wu Zhi (2010) modified the financial development variables, the analysis showed that the internal connection between finance and economy is not a simple one-way promotion, it is a two-way internal promotion. The research results of Duan Jin (2011) on Chang-Zhu-Tan area show that financial development can effectively promote regional economic growth. In turn, economic growth has further improved the level of financial development [28].

(5) Financial development hinders economic growth. The research results of Arestis and Demetriades (1997) show that not all regions have a positive relationship between financial development and economic growth. Moreover, due to the imperfection of the financial market, the capital market is distorted. The existence of this kind of suppression makes it impossible for a large number of small- and medium-sized enterprises to effectively obtain financing and funds, and various unfavorable factors in the existence of this has seriously hindered economic development. Krugman (1996) also believes that due to the uncertainty and risk of the financial market, the negative impact on the economy is great [29].

The construction of wireless network sensors and the use of RSSI ranging principles to predict and analyze financial development and economic growth, in-depth analysis and research of financial structure, financial development 
efficiency, and other content further verify that there is a close connection between financial development and economic growth. From this, it puts forward that China needs to continue to build the capital market, improve the asset structure, and deepen financial reforms. It is hoped that it can provide necessary assistance for the sound and rapid development of China's social economy.

The core effect of financial deepening on economic growth is to change the original financial structure model to create a production mechanism for realizing resources and have an impact on economic growth. As a branch of financial development theory, financial deepening theory is derived on the basis of financial development theory. In the West, some economists try to answer whether financial development is the first to promote real economic growth, or whether real economic growth promotes financial development.

\section{Empirical Research Experiment on the Relationship between Financial Development and Economic Growth Based on Intelligent Algorithms Based on Wireless Network Communication}

3.1. Experimental Summary. This experiment will briefly introduce the economic development level of the Yangtze River Delta, reflect the significance of the research to some extent, then introduce the level of financial development, and finally analyze the location, policy, and resource advantages of the Yangtze River Delta from the perspective of policy, historical culture, and geographical environment.

3.2. Experimental Process. As shown in Figure 3, it is the experimental flow chart of this article. The experiment of this article is divided into five parts. The first part clarifies and summarizes the current research status at home and abroad; the second part explains the concepts of financial development and economic growth theory and the relationship between the two. The third part analyzes the characteristics of the Yangtze River Delta's financial development and economic development based on the statistical data over the years, and it also clarifies the current financial development level and economic development status of the Yangtze River Delta. Chapter four empirically analyzes the relationship between financial development and economic growth.

3.3. Experimental Discussion. On the basis of existing research, a more in-depth and comprehensive analysis of the characteristics of financial development and economic development. First of all, it is very convincing to use the relevant data of the entire financial development and economic development of the Yangtze River Delta for many years to analyze. In order to avoid the deviation of the estimation results due to the endogeneity of panel data variables, this study uses financial deepening variables and all control variables as instrumental variables to perform panel data regression and prediction to reduce the

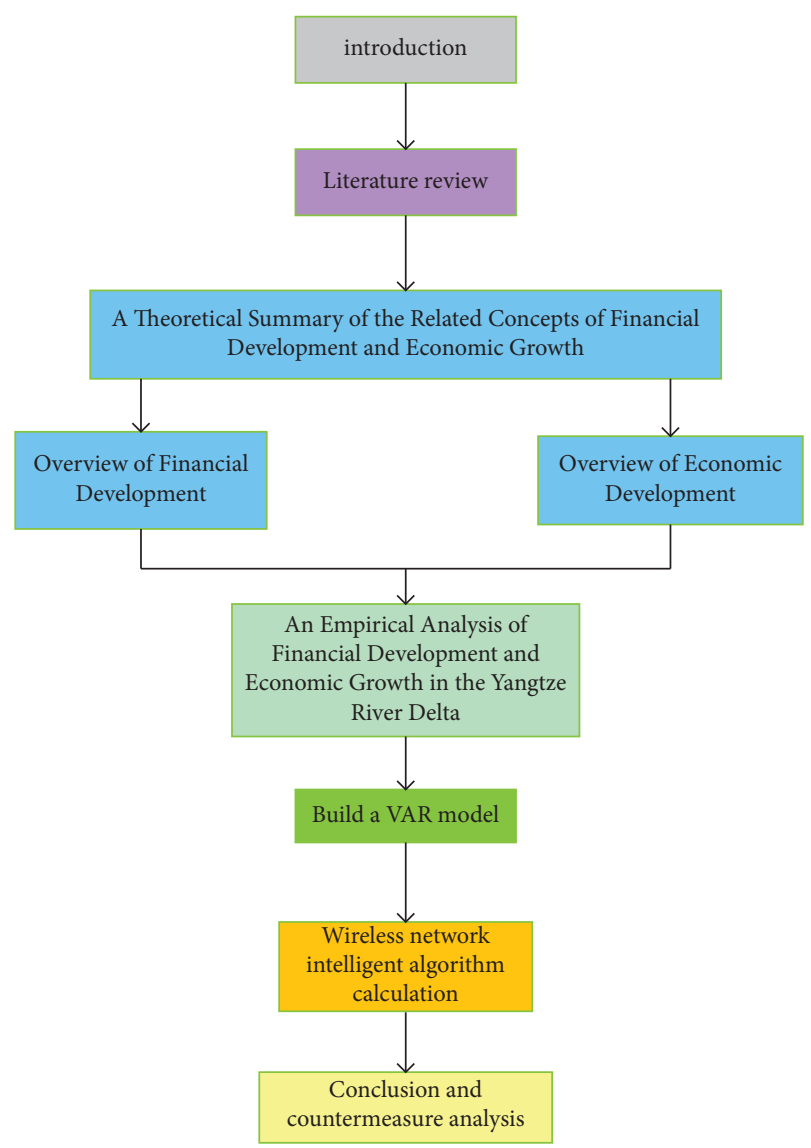

FIgURE 3: Experimental flowchart.

endogeneity between variables. It analyzes in detail the current status and characteristics of the financial development of the Yangtze River Delta from three aspects of the banking industry, securities industry, and insurance industry and summarizes the deficiencies in the economic and financial development of the Yangtze River Delta through a horizontal comparison with the national level. Using scatter plots, preliminary estimation of the relationship between financial development and economic growth was done in the Yangtze River Delta. Economic development, in turn, did not promote financial development. Through impulse test, variance decomposition, and error correction model, the current financial development has little effect on economic growth. Finally, combining statistics and empirical analysis, it puts forward relevant policy recommendations for coordinating financial development and promoting economic development in the Yangtze River Delta.

\section{Empirical Research and Analysis of the Relationship between Financial Development and Economic Growth Based on Intelligent Algorithms Based on Wireless Network Communication}

4.1. Regional Economic Development and Financial Development. Firstly, the economic development level of the Yangtze River Delta reflected the significance of the 
research to some extent, then the financial development level and finally the location, policy, and resource advantages from the perspective of policy, historical culture, and geographical environment. Because there are many factors that affect economic growth, the excessive number of control variables will cause the problem of multiple collinearities between variables. This study chooses the final consumption rate with low correlation coefficient, the initial level of economic growth, the proportion of fiscal expenditure in real GDP, and the labor force growth rate as the main control variables.

As shown in Figure 4, it is the comparison of the total GDP from 1978 to 1995 in the first stage. We can clearly see that due to historical reasons, the total GDP of Shanghai was the largest at the beginning, at 27.3 billion yuan; with the progress of reform and opening up, Jiangsu Province has exerted its potential demographic and other dividends and gradually caught up. Shanghai takes the lead in the delta of its GDP. At the end of this stage, Zhejiang's potential has also been fully explored, surpassing Shanghai in one fell swoop.

As shown in Figure 5, it is the comparison of the total GDP from 1996 to 2014 in the second phase. During this phase, with the comprehensive deepening of reform and opening up, the economies of the three regions have developed rapidly. Jiangsu Province still maintains a strong momentum and ranks first in the total amount. At the end of 2014, the total GDP reached 658.8 billion yuan, an increase of $974 \%$ from 605.7 billion yuan in 1996; Zhejiang Province also came from behind and ranked second. The total GDP at the end of 2014 was 4,015.3 billion yuan, an increase of $858 \%$ from 418.8 billion yuan in 1996; the growth rate of Shanghai during this period reached $696 \%$.

As shown in Table 1, the average annual growth rate shows a trend of rapid growth, from the initial annual growth rate of 14.6 billion yuan to the current annual growth rate of 4031.7 billion, which is an increase of 27.8 times. This shows that after the reform and opening up, the level of financial development has experienced a rapid development stage.

Figure 6 shows the comparison of the deposit and loan balances of the provinces and cities in the Yangtze River Delta. From the figure, we can clearly see that the beginning of reform and opening up in 1978, due to historical reasons, created Shanghai's leading position; with the reform and opening up in 1984, Jiangsu Province came from behind. In 1984, the deposit and loan balance surpassed Shanghai for the first time; at the same time, Zhejiang Province also grew steadily.

As shown in Figure 7, with the further deepening of reform and opening up, at the beginning of the second stage (1990-2001), the total deposit and loan balance of Shanghai returned to the first position, and within this time interval, the gap is slowly widening; at the same time, Jiangsu Province and Zhejiang Province are both growing steadily. Jiangsu Province has always maintained the second position, and the gap between Zhejiang Province and Zhejiang Province is gradually decreasing.

When the domestic currency is in the initial state of depreciation, the three curves of our country intersect at one point, that is, the commodity market and the foreign exchange market and the currency market are in equilibrium. When the domestic economy is in recession, and there is a fiscal deficit, the domestic currency will depreciate, and the intersection will move toward Move down. However, due to government control, the domestic interest rate is guaranteed to remain unchanged. When the central bank implements an expansionary fiscal policy, the increase in the supply of real money causes the LM curve to shift to the right, and the real interest rate falls. There is a deficit in international trade, and total demand is less than total supply. As shown in Figure 8, after entering the third stage (2002-2014), with the comprehensive deepening of reforms and the full penetration of opening up, the gap between the three regions is getting smaller and smaller. Finally, Jiangsu Province is far ahead of the number one. Secondly, Zhejiang Province also surpassed Shanghai in one fell swoop and came to the second position.

4.2. Algorithm Performance Analysis. As shown in Figure 9, the left picture shows the relationship between the number of anchor nodes and the positioning accuracy, and the right picture shows the relationship between anchor nodes and the positioning coverage. As can be seen from the figure, the overall positioning accuracy of the improved algorithm is better than the other two algorithms. The node positioning coverage of the improved algorithm is higher than that of the traditional RSSI trilateral positioning algorithm. When the number of anchor nodes is 5, the traditional trilateral positioning algorithm can no longer accurately locate the node position, and the positioning coverage is basically 0 . With the increase of the number of anchor nodes, the improved algorithm can reach a higher coverage rate faster. When the anchor node density is $30 \%$, the coverage rate is close to $100 \%$. The reason why the number of anchor points affects it is because once the number of anchor points is too large, both the stability of the network and the calculation speed will be affected by the number of anchor points, so the positioning accuracy and positioning coverage will change again.

As shown in Table 2, it can be seen from the data results that the computational complexity of the weighted centroid location algorithm is much lower than the other two algorithms, but it can be seen that its location accuracy is the lowest. Although the positioning algorithm in this study uses the particle swarm optimization algorithm, it does not increase the computational complexity of the algorithm. The computational complexity of the overall algorithm is slightly lower than that of the traditional trilateral positioning algorithm.

As shown in Figure 10, it is a graph describing the variation of the average positioning error with the change of the anchor node and the communication radius. As can be seen from the figure, the algorithm in this study has the highest positioning accuracy, which is $68 \%$ higher than the DV-Hop algorithm, $62 \%$ higher than the positioning algorithm 1, and $25 \%$ higher than the positioning algorithm 2 . Compared with the other three algorithms, the positioning accuracy of the algorithm in this study is very stable, and the changes are small. It can be seen from the figure on the right 


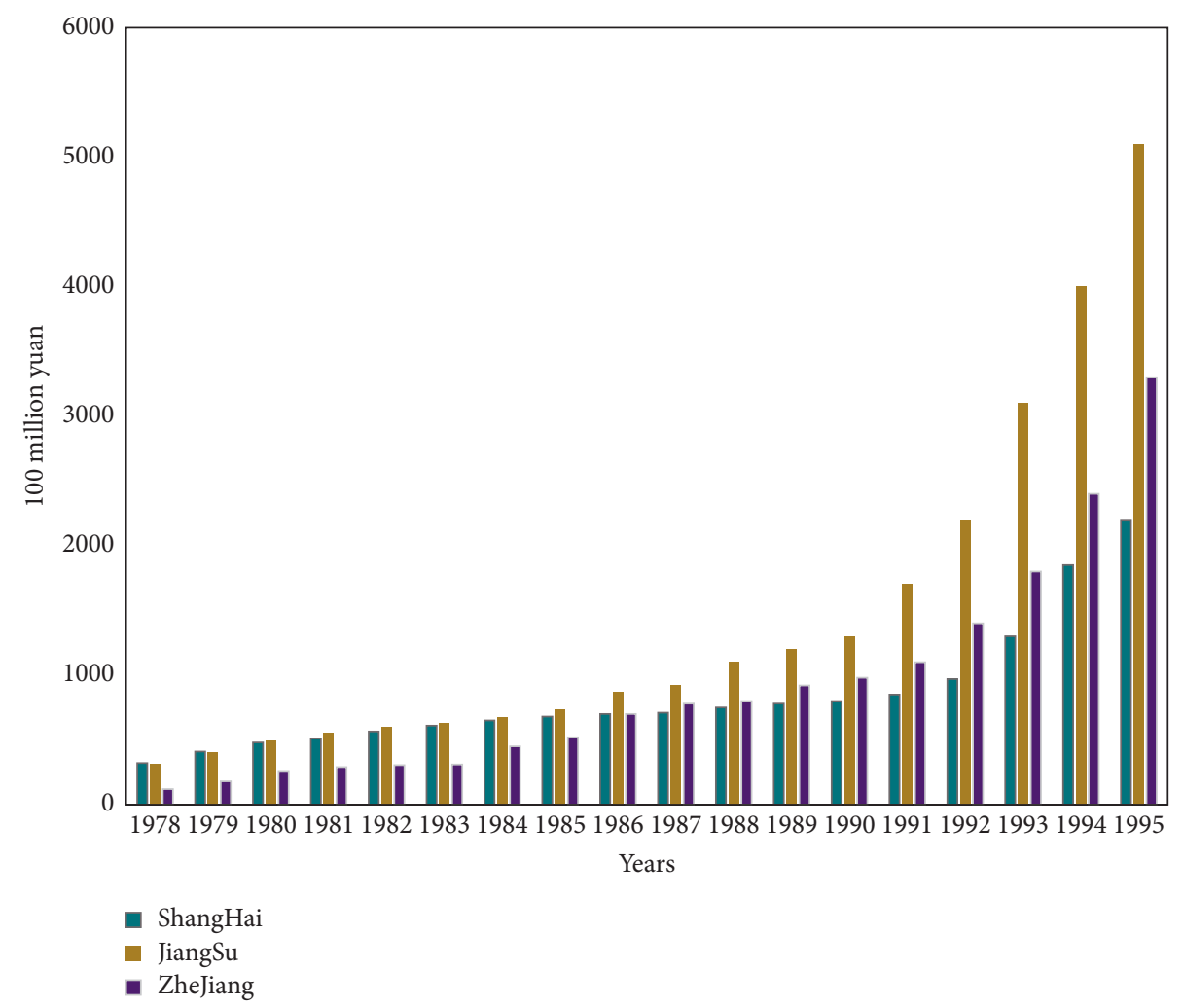

Figure 4: Comparison of total GDP of various provinces and cities in the Yangtze River Delta (1978-1995).

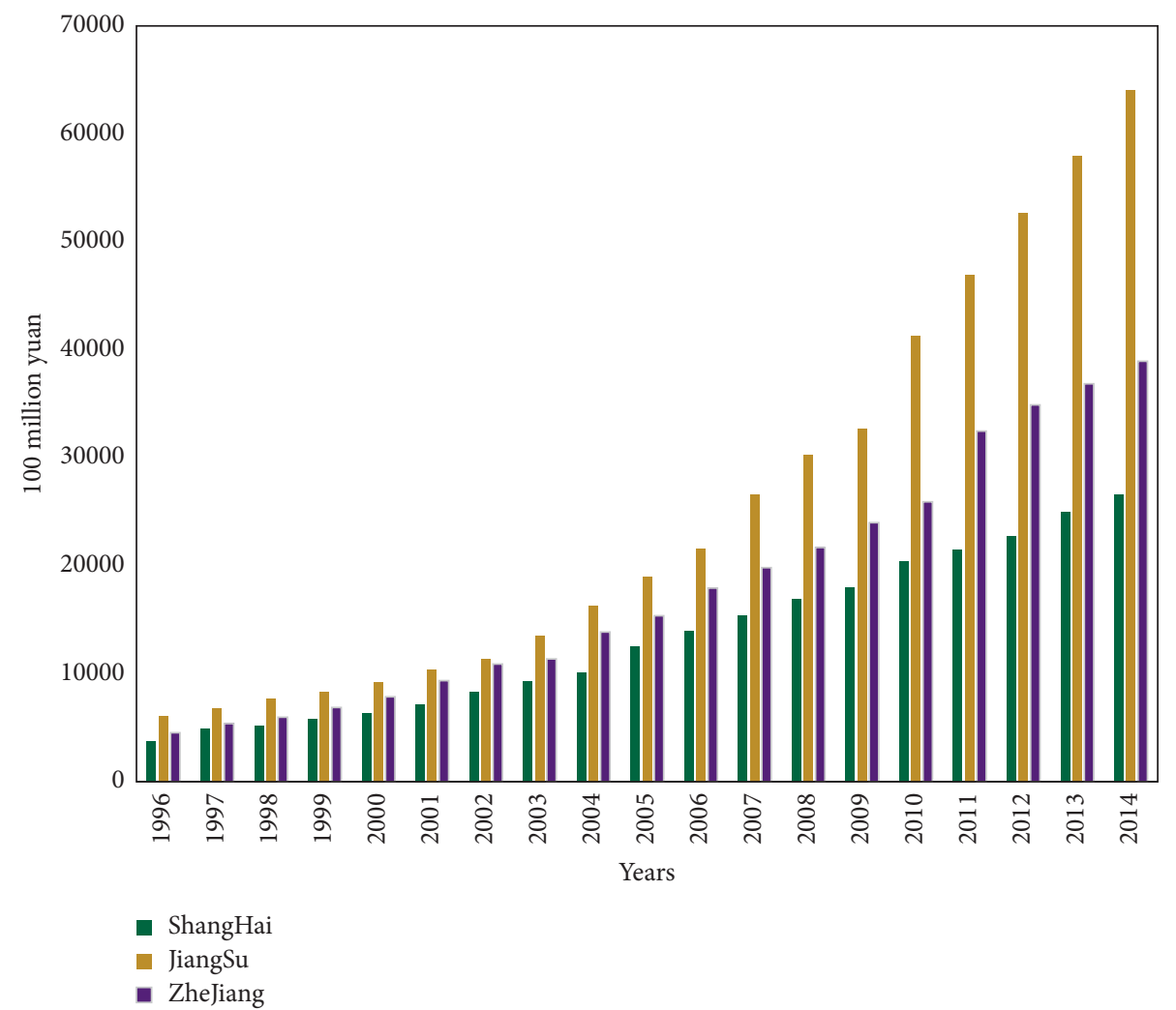

Figure 5: Comparison of total GDP of various provinces and cities in the Yangtze River Delta (1996-2014). 
TABLE 1: The average annual growth rate of deposits and loans.

\begin{tabular}{lccc}
\hline Years & Deposit and loan balance (100 million yuan) & Increase (100 million yuan) & Average growth rate (100 million yuan/year) \\
\hline 1978 & 659 & $/$ & $/$ \\
1988 & 2153 & 1468 & 146.8 \\
1998 & 31967 & 29861 & 2986.1 \\
2008 & 187641 & 156127 & 15612.7 \\
2014 & 432921 & 243591 & 40317 \\
\hline
\end{tabular}

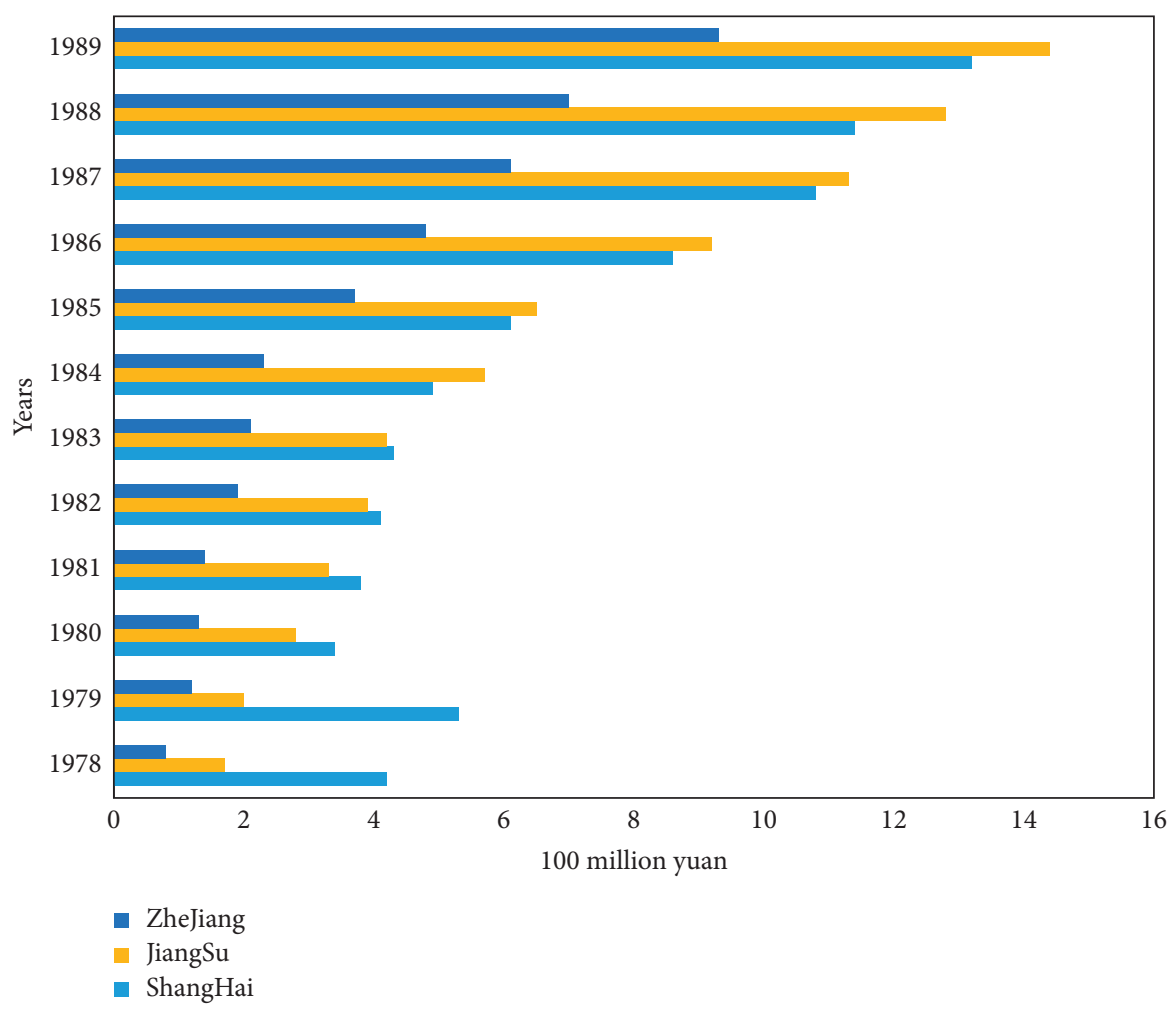

Figure 6: Comparison of deposit and loan balances among provinces and cities in the Yangtze River Delta (1978-1989).

that the positioning accuracy of the four algorithms has declined because as the communication radius increases, the hop distance will also increase.

As shown in Figure 11, the left figure shows that the average positioning error changes with the number of nodes. The number of nodes increases from 100 to 300. As the number of nodes increases, the hop distance between networks becomes more accurate, and the average positioning error shows a decrease. It can be seen from the figure on the right that it is the location error map of the unknown nodes of the four algorithms. It can be seen that the location algorithm 2 is the algorithm with the largest fluctuation, and its maximum fluctuation value can reach more than $33.8 \mathrm{~m}$ but only $0.13 \mathrm{~m}$ at the lowest. The algorithm in this study is the algorithm with the smallest fluctuation range. The improved algorithm in this study is generally very stable, with fluctuations around $3 \mathrm{~m}$. Therefore, the algorithm not only has good stability but also greatly reduces the positioning error of unknown nodes.
As shown in Figure 12, under the number of 100, 120, 140 , and 160 nodes, the calculation time required for the four algorithms to run, it can be seen that the DV-Hop algorithm has the least calculation time, followed by the positioning algorithm 2, and then there is the improved algorithm of this article, and the slowest is the positioning algorithm 1. The communication radius of the running calculation selected here is $30 \mathrm{~m}$, and the anchor node is $10 \%$. Compared with the positioning algorithm 1, the algorithm in this study speeds up the convergence speed and reduces the time by about $35 \%$. It can be seen from the above figures that the algorithm runs longer than the positioning algorithm. Algorithm 2 is long, but the overall positioning accuracy is higher than that of the positioning algorithm, which is about $20 \%$ higher. However, the total GDP of these regions cannot be clearly representative. After data analysis, it is found that when the growth of the money supply is too high or too low, the economic growth is not significantly affected by financial deepening. 


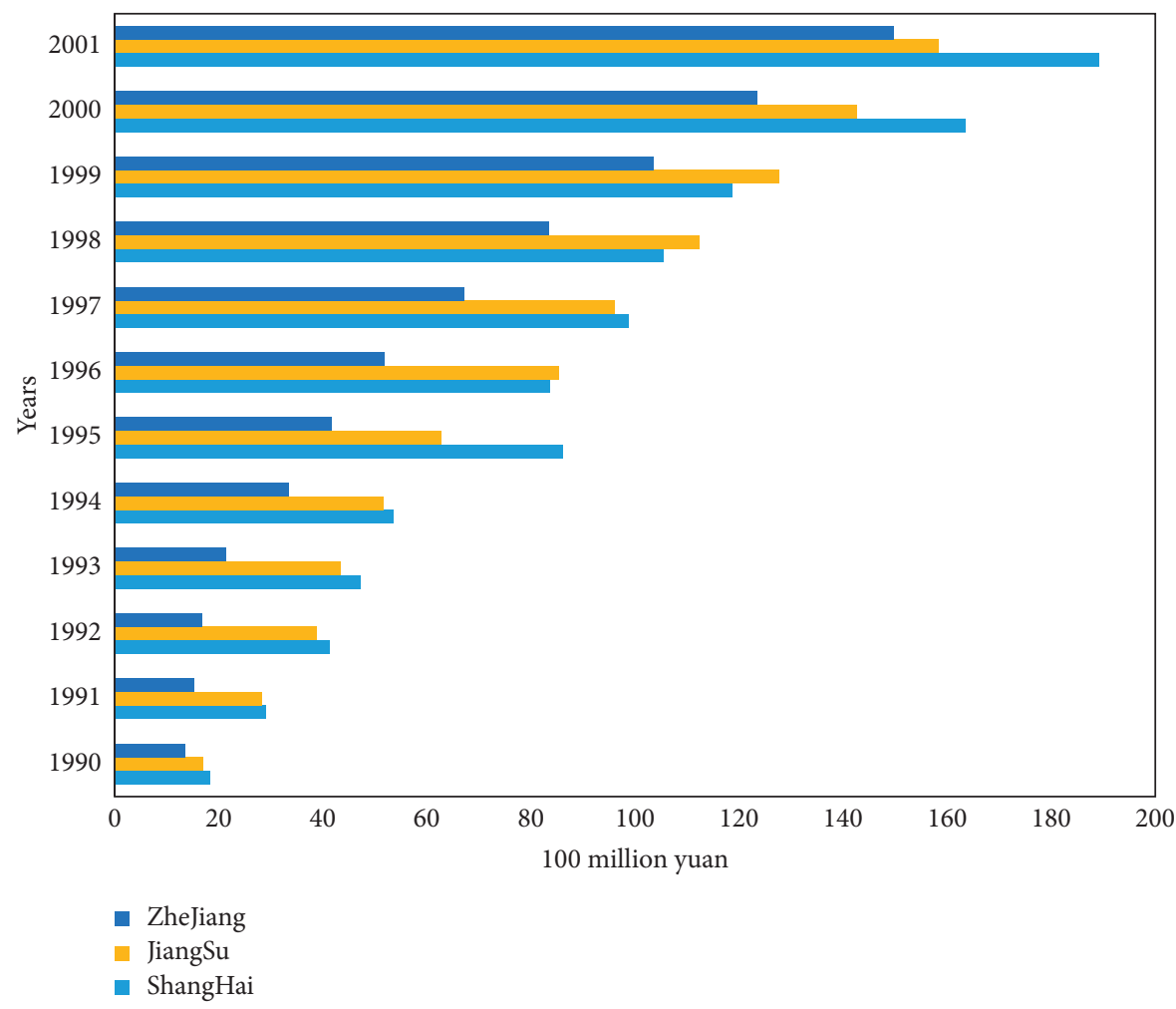

FIgURE 7: Comparison of deposit and loan balances of provinces and cities in the Yangtze River Delta (1990-2001).

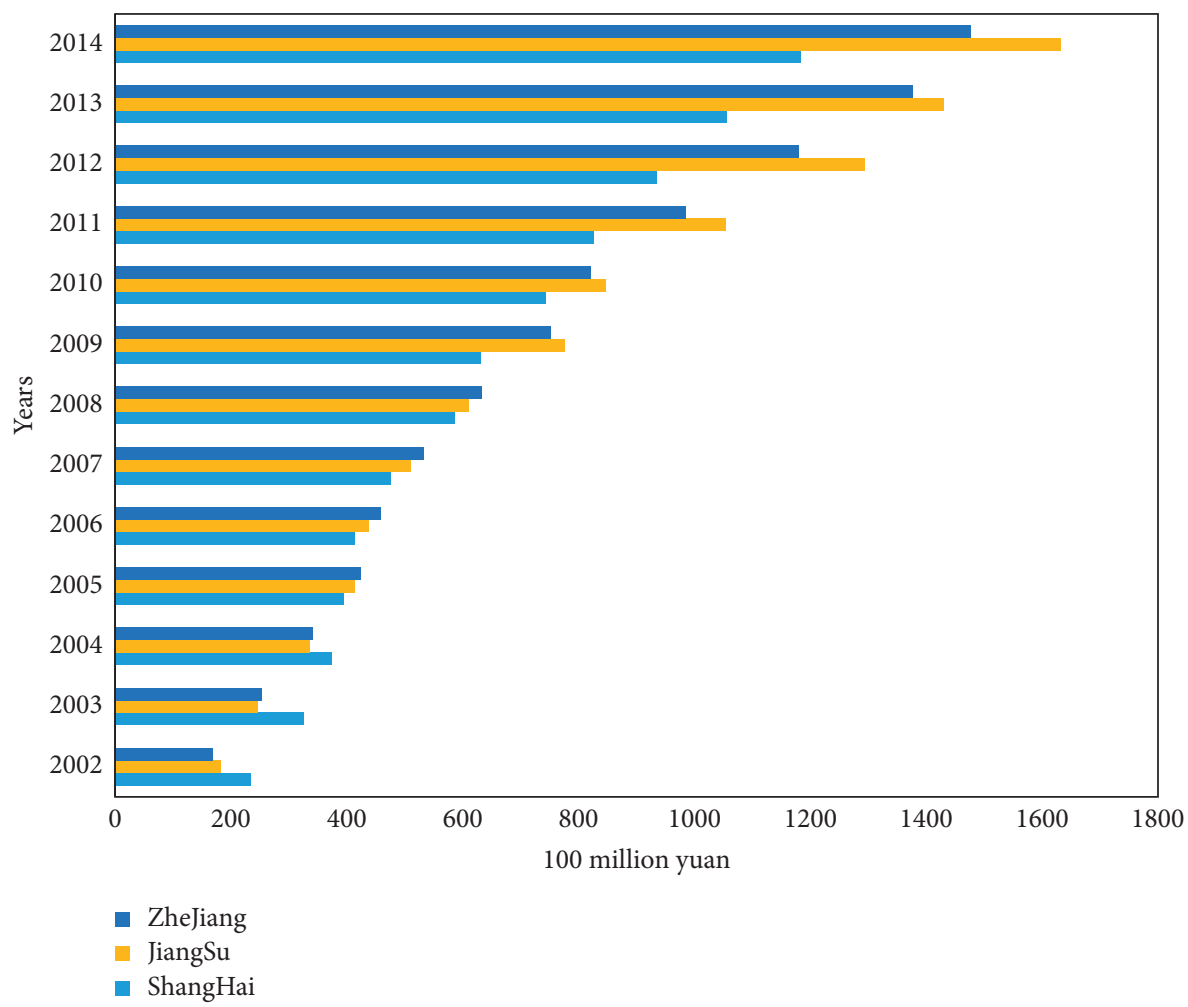

Figure 8: Comparison of deposit and loan balances among provinces and cities in the Yangtze River Delta (2002-2014). 


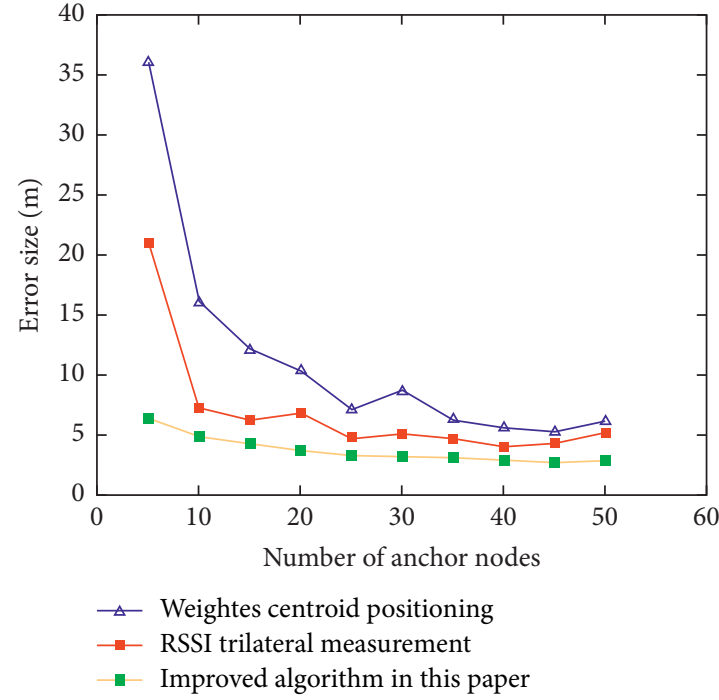

(a)

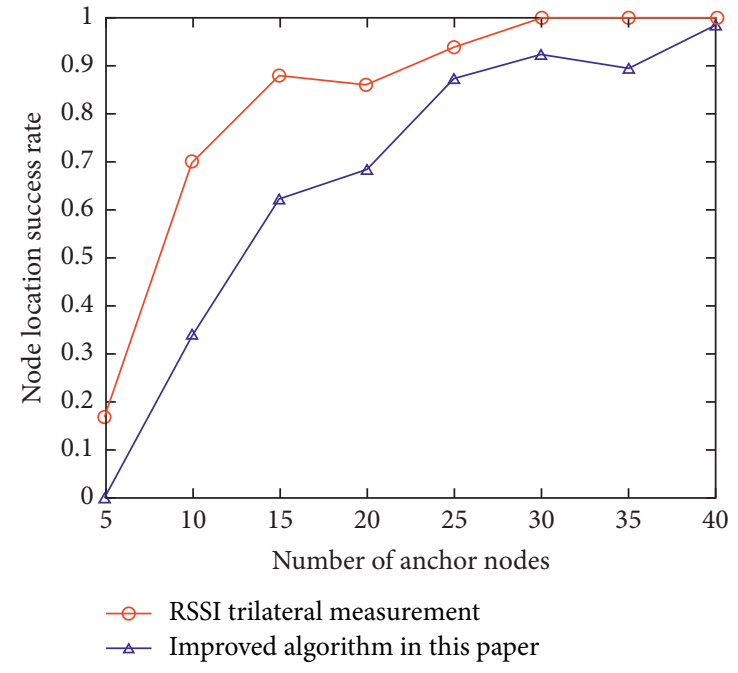

(b)

FIGURE 9: The relationship between the number of anchor nodes and positioning accuracy (a). The relationship between anchor nodes and positioning coverage (b).

TABLE 2: Average computing time under different nodes.

\begin{tabular}{|c|c|c|c|c|}
\hline Number of nodes & $100(\mathrm{~s})$ & $120(\mathrm{~s})$ & $140(\mathrm{~s})$ & $160(\mathrm{~s})$ \\
\hline Weighted centroid positioning & 0.567 & 0.793 & 1.134 & 1.536 \\
\hline Trilateral positioning algorithm & 68.493 & 90.175 & 105.631 & 123.156 \\
\hline Improved algorithm in this study & 50.689 & 71.634 & 92.679 & 117.621 \\
\hline Updated algorithm & 31.257 & 60.124 & 88.546 & 109.521 \\
\hline
\end{tabular}

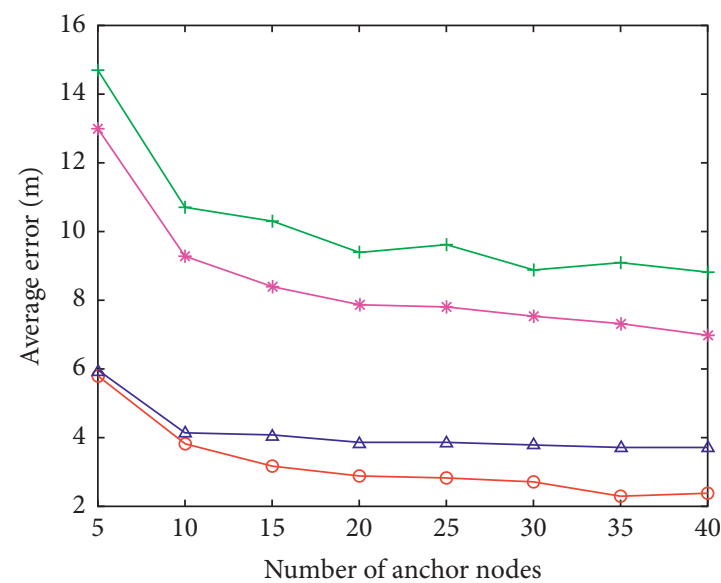

$$
\begin{array}{ll}
- \text { Algorithm } & * \text { Positioning algorithm } 1 \\
\triangle \text { dv-hop } & + \text { Positioning algorithm } 2
\end{array}
$$

(a)

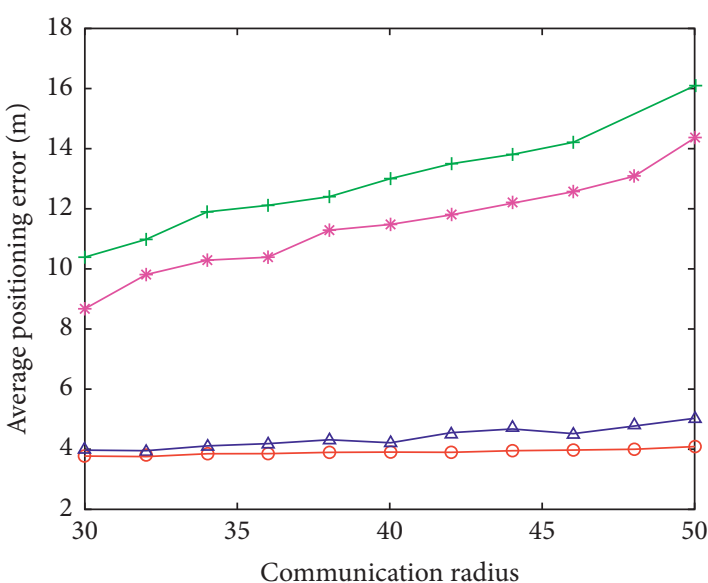

$\begin{array}{ll}\multimap \text { Algorithm } & * \text { Positioning algorithm } 1 \\ \triangle \text { dv-hop } & + \text { Positioning algorithm } 2\end{array}$

(b)

FIgURE 10: The average positioning error varies with the number of anchor nodes (a). The average positioning error varies with the communication radius (b). 


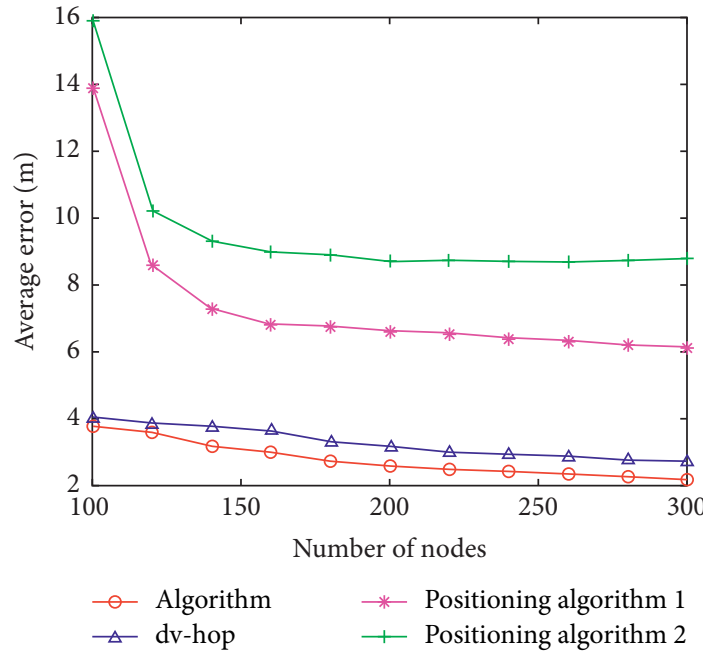

(a)

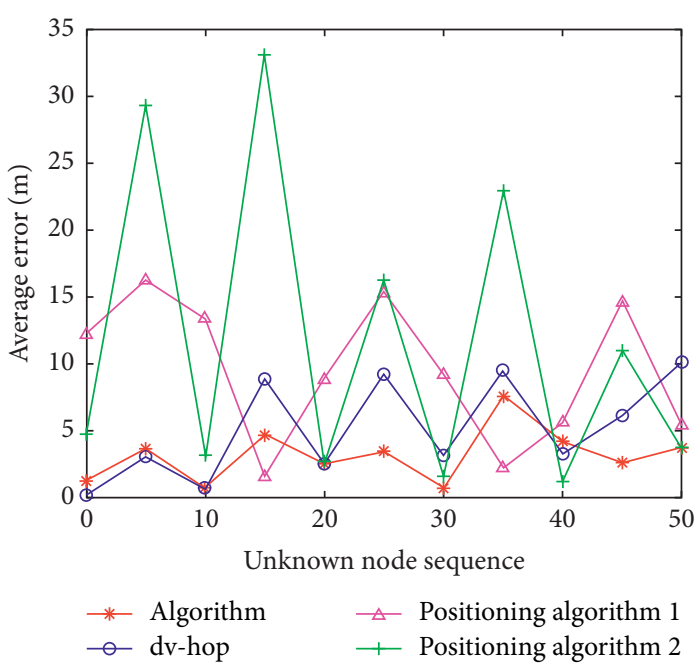

(b)

FIGURE 11: The variation of the average positioning error with the number of nodes (a). The comparison chart of the positioning errors of unknown nodes (b).
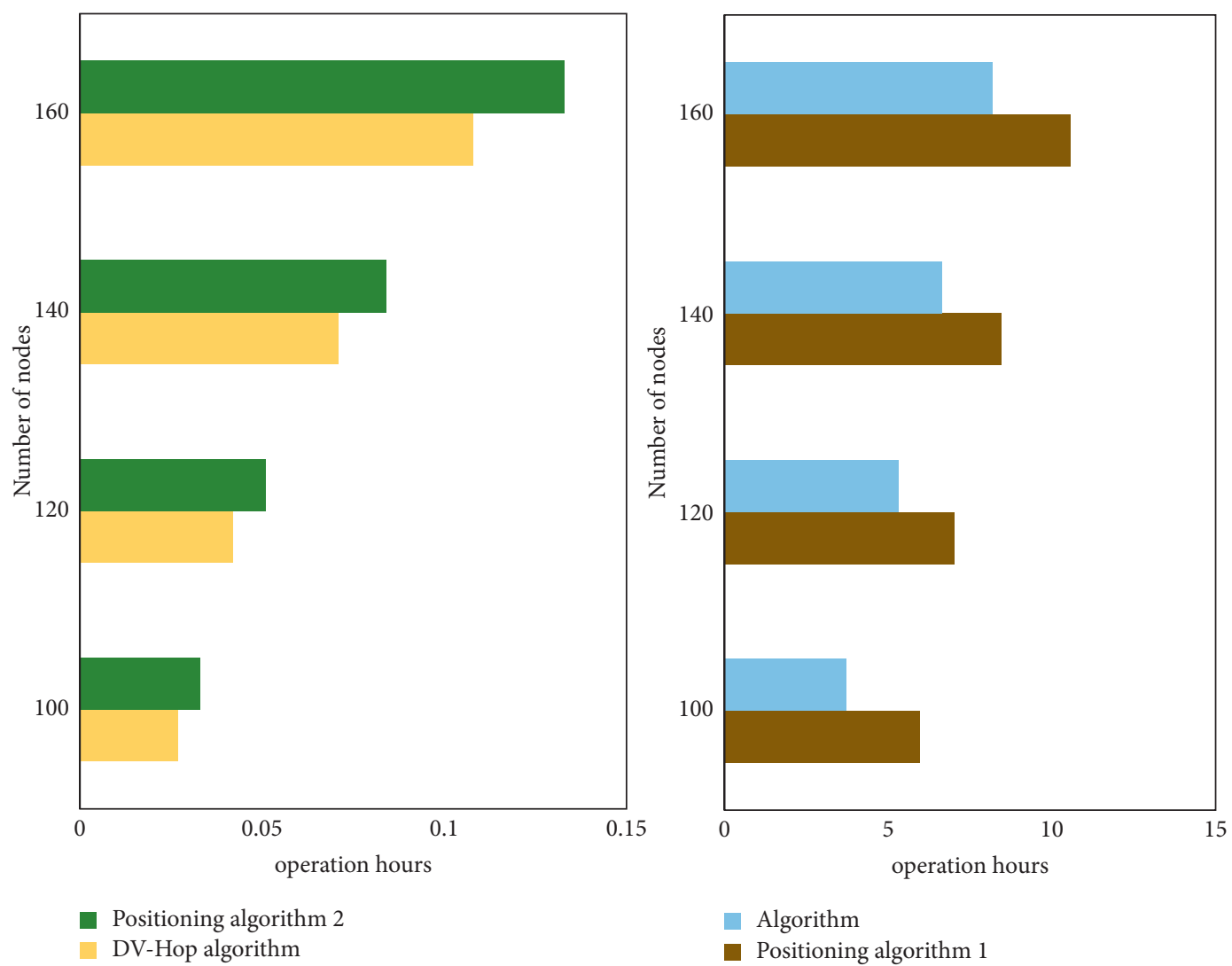

FiguRE 12: Average computing time under different nodes.

\section{Conclusion}

When this study conducted empirical research on the relationship between financial development and economic growth, it started from the two perspectives of the scale of financial assets and the efficiency of financial intermediaries.
On the basis of the VAR model, the problem is analyzed using a series of test methods. Using the macroeconomic data at the interprovincial and regional levels, the overall financial development and economic growth of the region are used to compare and analyze the research results between regions. The empirical results show that the financial 
sector provides capital for entrepreneurial development for potential industrial sectors, thereby activating the national economy. At this point, both the overall inspection results of the Yangtze River Delta region, or the inspection results of Jiangsu Province and Zhejiang Province can be clearly reflected. The panel data threshold model is used to test the growth rate of the indicator money supply, and the results show that.

In the relationship between financial deepening and economic growth, there are two upper and lower thresholds for the growth rate of money supply. When the money supply is too high, inflation caused by the excessive money supply will cause imbalance and chaos in the economic order, which will have an impact on demand, trigger a lot of speculation, and reduce the overall resource utilization efficiency of the society. The biggest shortcoming of this article is that it fails to portray the connotation of financial development from multiple angles. The use of intelligent optimization algorithms will increase the computational time complexity of the algorithm and affect the energy of the node. It should reduce the individual feasibility area to meet the requirements of high-precision positioning. Because the database selects data samples from various provinces and regions across the country, there are many limitations on the data source. The sample itself has a short time span, the database is not updated in time, and data come from multiple databases, which makes the research of this article possible to have certain errors. This article is subject to objective adjustments in the research process, and there are certain limitations and shortcomings, which need to be improved in future research.

\section{Data Availability}

The data that support the findings of this study are available from the corresponding author upon reasonable request.

\section{Conflicts of Interest}

The author(s) declared no potential conflicts of interest with respect to the research, author-ship, and/or publication of this article.

\section{Acknowledgments}

The author(s) received no financial support for the research, authorship, and/or publication of this article.

\section{References}

[1] V. Swaour and M. Dharani, "An alternate approach in exploring the causal link between financial development and economic growth-evidence from advanced economies," International Journal of Finance and Economics, vol. 23, no. 1, pp. 55-76, 2018.

[2] B. Nkoa, "Determinants of foreign direct investment in Africa: an analysis of the impact of financial development," Economics Bulletin, vol. 38, no. 1, pp. 221-233, 2018.

[3] M. Kalloub, A. Musabeh, and K. Alrifai, "Financial development, economic growth and welfare: evidence from emerging countries," Pressacademia, vol. 9, no. 2, pp. 118-131, 2020.

[4] S. Nyasha and N. M. Odhiambo, "Financial development and economic growth nexus: a revisionist approach," Economic Notes, vol. 47, no. 1, pp. 223-229, 2018.

[5] H. Esmaeilpour Moghadam and V. Dehbashi, "The impact of financial development and trade on environmental quality in Iran," Empirical Economics, vol. 54, no. 4, pp. 1777-1799, 2018.

[6] S. Dewi, M. S. Abd Majid, S. Aliasuddin, and S. Kassim, "Dynamics of financial development, economic growth, and poverty alleviation: the Indonesian experience," South East European Journal of Economics and Business, vol. 13, no. 1, pp. 17-30, 2018.

[7] S. Riache, B. Louail, and C. Beggache, "Causal dynamics between foreign direct investment, economic growth and financial development in Algeria during 1970-2017," SMART Journal of Business Management Studies, vol. 17, no. 1, pp. 103-116, 2021.

[8] S. Küüksakarya, "A panel causality analysis of the relationship between financial development and economic growth in OECD countries," Business and Management Studies an International Journal, vol. 9, no. 2, pp. 662-672, 2021.

[9] H. Hasan, M. S. Oudat, A. A. Alsmadi, M. Nurfahasdi, and B. J. A. Ali, "Investigating the causal relationship between financial development and carbon emission in the emerging country," Journal of Governance and Regulation, vol. 10, no. 2, pp. 55-62, 2021.

[10] K. Kumar, R. N. Paramanik, and R. N. Paramanik, "Nexus between Indian economic growth and financial development: a non-linear ARDL approach," The Journal of Asian Finance, Economics and Business, vol. 7, no. 6, pp. 109-116, 2020.

[11] Y. Keho, "Impact of remittances on financial development: revisiting the evidence for ECOWAS countries," Theoretical Economics Letters, vol. 10, no. 1, pp. 169-179, 2020.

[12] H.-u. Rahman, A. Ghazali, G. A. Bhatti, and S. U. Khan, "Role of economic growth, financial development, trade, energy and FDI in environmental kuznets curve for Lithuania: evidence from ARDL bounds testing approach," Engineering Economics, vol. 31, no. 1, pp. 39-49, 2020.

[13] J. A. Fuinhas, M. Koengkan, and M. Belucio, "Exploring the causality between economic growth, financial development and inflation in sixteen high-income countries," Revista de EstudosSociais, vol. 22, no. 45, pp. 1-13, 2021.

[14] N. Ramu, V. Pandi, J. D. Lazarus, and S. Radhakrishnan, “A novel trust model for secure group communication in distributed computing," Journal of Organizational and End User Computing, vol. 32, no. 3, pp. 1-14, 2020.

[15] M. Faheem, I. S. Chaudhry, and S. Hussain, "Natural resources, institutional quality and financial development in GCC member countries: visiting 'resource curse hypothesis' by DCCE estimation," Review of Economics and Development Studies, vol. 7, no. 2, pp. 131-145, 2021.

[16] F. Afridi, "The unrevealing nexus between foreign direct investments, institutional quality and financial development in Pakistan," Revista Amazonia Investiga, vol. 09, no. 36, pp. 22-37, 2020.

[17] S. S. Gill and A. Shaghaghi, "Security-aware autonomic allocation of cloud resources," Journal of Organizational and End User Computing, vol. 32, no. 3, pp. 15-22, 2020.

[18] G. C. Shreezal, "Relationship between trade openness, financial development and economic growth of Nepal: evidence from a developing country," Quest Journal of Management and Social Sciences, vol. 2, no. 2, pp. 206-224, 2020. 
[19] F. M. Ahmed, D. M. Hadi, and A. K. Ahmed, "Impact of economic growth, financial development, and trade openness on environmental degradation in Egypt," Polytechnic Journal, vol. 10, no. 1, pp. 98-102, 2020.

[20] P. Kombo and G. B. Koumou, "The role of the quality of institutions in the financial development of CEMAC countries," Modern Economy, vol. 12, no. 2, pp. 452-468, 2021.

[21] M. S. Hossin, "Interest rate deregulation, financial development and economic growth: evidence from Bangladesh," Global Business Review, vol. 24, no. 1, pp. 1-14, 2020.

[22] A. Muneeb, M. Qamruzzaman, and S. Ayesha, "The role of remittances in financial development: evidence from nonlinear ARDL and asymmetric causality," Journal of Asian Finance Economics and Business, vol. 8, no. 3, pp. 139-0154, 2021.

[23] N. Baskaran and R. Eswari, "Efficient VM selection strategies in cloud datacenter using fuzzy soft set," Journal of Organizational and End User Computing, vol. 33, no. 5, pp. 153-179, 2021.

[24] F. Ayivodji, R. Hounsou, and E. Tago, "Analysis of the relationship between financial development, employment and institutions on economic growth in WAEMU countries," Archives of Business Research, vol. 7, no. 12, pp. 267-291, 2020.

[25] S. Maheswaranathan and K. M. N. Jeewanthi, "The contribution OF FDI and financial development ON economic growth IN Sri Lanka," International Journal of Engineering Technologies and Management Research, vol. 8, no. 1, pp. 25-34, 2021.

[26] C. Maican, A.-M. Cazan, R. Lixandroiu, L. Dovleac, and M. A. Maican, "Exploring the factors influencing the use of communication and collaboration applications," Journal of Organizational and End User Computing, vol. 33, no. 4, pp. 94-124, 2021.

[27] I. D. Lestari, N. Effendi, and A. F. Priyono, "Financial development, economic growth, and environmental degradation nexus in ASIAN emerging markets," Jurnal Ekonomi Pembangunan, vol. 18, no. 2, pp. 177-189, 2020.

[28] Q. Jiang, X. Zhang, Q. Lin, G. Chen, R. Zhang, and S. Liu, "Internet penetration and regional financial development in China: empirical evidence based on Chinese provincial panel data," Scientific Programming, vol. 2020, no. 8, pp. 1-14, 2020.

[29] P. Stamatiou and M. Papadopoulou, "Financial development and economic growth: evidence from the eurozone," International Journal of Accounting and Finance Studies, vol. 4, no. 1, pp. 7-16, 2021. 